\title{
sciendo
}

CIVIL AND ENVIRONMENTAL ENGINEERING REPORTS

E-ISSN 2450-8594

CEER 2019; 29 (3): 060-069

DOI: 10.2478/ceer-2019-0024

Original Research Article

\section{THE PERFORMANCE OF EXTRACELLULAR POLYMERIC SUBSTANCE (EPS) ON STABILITY OF AEROBIC GRANULAR SLUDGE (AGS)}

\author{
Hamiruddin $\mathrm{NA}^{1}$, Awang $\mathrm{NA}^{1,2^{*}}$, Shaaban $\mathrm{MG}^{2}$ \\ ${ }^{1}$ School of Civil Engineering, Engineering Campus, Universiti Sains Malaysia, \\ Nibong Tebal, 14300 Pulau Pinang, Malaysia \\ ${ }^{2}$ Department of Civil Engineering Faculty of Engineering, University of Malaya, 50603 \\ Kuala Lumpur, Malaysia
}

\begin{abstract}
Various article which indicating the Aerobic granular sludge (AGS) instability, particularly in prolonged phase operating duration become a significant obstacle to its implementation. Generally, prolonged the operation period will lost its stability that can degrade performance effectiveness. As AGS stabilization in hydrodynamic shear force and resisting mass transfer resistance within the reactor generally defined or evaluated by microbial community, bioactivity, extracellular polymeric substance (EPS) structure and granular aspect. The aim of this research in order to illustrate the EPS formation on AGS which is preserved at $4{ }^{\circ} \mathrm{C}$ in sequencing batch reactor (SBR) by sewage for eight months. The effective of granulation method and redevelopment of AGS stability by particular pressure produced with several hydrodynamic shear force and mass transfer resistance which controlled by low organic loading rate (OLR) between 0.26 and $0.81 \mathrm{~kg}$ CODs $/ \mathrm{m}^{3}$ $\mathrm{d}$ with $1.33 \mathrm{~cm} / \mathrm{s}$ of superficial air velocity (SAV). The confocal laser scanning microscope (CLSM), Fourier transform infrared (FTIR), and energy dispersive X-ray spectrometer (EDX) were implemented to notice the evolution in composition of EPS that
\end{abstract}

\footnotetext{
${ }^{1}$ Corresponding author: School of Civil Engineering, Engineering Campus, Universiti Sains Malaysia, Nibong Tebal, 14300 Pulau Pinang, Malaysia, e-mail: cenikazimatol@usm.my, tel: +6045996213 ,
} 
revealed the intermolecular interaction helped the aerobic granule stability as seed to achieved the performance of EPS on stability of AGS.

Keywords: Extracellular polymeric substance, Aerobic granular sludge, Stability

\section{INTRODUCTION}

An under various operating conditions and types of substrates the aerobic granule sludge (AGS) can be develop. Nevertheless, several news indicating the AGS instability, particularly in the long phrase operating duration become a significant obstacle to its implementation as it was affected to separation of solid-liquid methodically (Miao et al. 2019). Reactor-formed aerobic granules was include of microbial communities that remove phosphorus and nitrogen, accumulate glycogen, and degrade the carbon sources along with remove autotrophic nitrogen through anammox system (Seviour et al. 2012). Therefore, it was viable to describe the aerobic granules stabilization to withstand mechanical and hydrodynamic shear force (Sheng et al. 2010). As AGS stabilization in hydrodynamic shear force and resisting mass transfer resistance within the reactor generally defined or evaluated by community of microbial, bioactivity, extracellular polymeric substance (EPS) structure or granular aspect (Chen et al. 2007).

In spite of the EPS impacts on biofilm thus, an anaerobic granule are recognized well in 2001 by Tay et al. (2001) when submitted an early report in exploring the EPS efficiency in aerobic granule formation and stability. The corresponding overcome by Wang et al. (2005) showed that EPS commits compelling to the stability of microbial granules which also similar to study by (Mcswain et al. 2005). An accelerated research was devoted to characterizing the performance of EPS by aerobic granules formation and stabilization. Several researcher such as Adav et al. (2008) and Lee et al. (2010) published an extensive evaluation of the EPS extraction procedure or properties of aerobic granules instead of its performance in growth and stability. In the study of Pishgar et al. (2018) noted that in prolonged phase AGS quickly to form instability contrasted with conventional activated sludge system.

However, knowledge of the AGS system's ability to regain the process of granulation which is instability a scarce stayed as present study work on extended variety of organic loading rate (OLR) over a duration of time (over 2 months) was infrequently highlighted (Liu and Tay 2004; Val Del Río et al. 2013). An article by Nancharaiah and Reddy (2018) recommended the next study of aerobic granules need to aimed the development mechanisms of formation, raise the aerobic granules development at low-strength sewage and the broad distributed on aerobic granule systems in treatment of sewage and industrial wastewater. 
The purpose of this research is to report the AGS by EPS structure and distribution in order to achieved re-granulated by various pressure within 0.26 and $0.81 \mathrm{~kg}$ $\mathrm{CODs} / \mathrm{m}^{3} \mathrm{~d}$ with $1.33 \mathrm{~cm} / \mathrm{s}$ of superficial air velocity (SAV) through sequencing batch reactor (SBR) under low OLR. The outcome of granulation method and redevelopment stability of AGS by particular pressure was highlighted by the study of (Awang et al. 2007).

\section{MATERIAL AND PROCEDURES}

A laboratory-scale of SBR with 4.0 L of working volume and $10 \mathrm{of} H / \mathrm{D}$ ratio was used in this research. Next, $1.0 \mathrm{~L}$ by aerobic granules was preserved at $4{ }^{\circ} \mathrm{C}$ as seeds within eight months rather as an activated sludge during the start-up. The size of seeds between 154 to $374 \mu \mathrm{m}$ were re-activated through 24 (hours) aeration, leading in an early concentrated by $0.7 \mathrm{~g} / \mathrm{L}$ of mixed liquor suspended solids (MLSS).

The procedure outlined for EPS extraction by Adav and Lee (2008) followed the ultrasound-formamide-sodium hydroxide $(\mathrm{NaOH})$ technique. Firstly, about 0.06 $\mathrm{m} / \mathrm{L}$ formamide $36.5 \% \mathrm{GC}$ by Sigma were added to $10 \mathrm{ml}$ of aerobic granules and leave for an hour at $4^{\circ} \mathrm{C}$. Next, the mixture was sonicated at $50 \mathrm{~W}$ within 5 minutes in ice bath. Then, $1 \mathrm{ml}$ of $\mathrm{NaOH}$ was added to the mixture and leave for an hour at $4^{\circ} \mathrm{C}$. Later, the mixture was centrifuged for 20 minutes at $10,000 \mathrm{~g}$ and $4^{\circ} \mathrm{C}$. The supernatant were filtered through $0.2 \mu \mathrm{m}$ membrane to collect soluble components. Finally, the EPS samples were stored at $-20^{\circ} \mathrm{C}$ until the test is performed.

The EPS of functional groups have been analyzed in a spectrum of $4000-400$ $\mathrm{cm} / \mathrm{s}$ Fourier transform infrared (FTIR) whereas the compositions of elements of aerobic granules then examine by energy dispersive X-ray spectrometer (EDX). Dispersion in aerobic granules of protein, active cells, and B-polysaccharides was imaged next to multicolor staining system as outlined by Chen et al. (2007). In current research, a kit from Life Technologies was FITC (Product ID, F6434) and SYTO 63 (Product ID, S11345). Whereas Calcofluor white was purchased from Sigma (Product ID, 18909). Then, the stained aerobic granules were stored at a temperature of $4^{\circ} \mathrm{C}$. Analysed image sample using confocal laser scanning microscope (CLSM) by Leica Tcs Sp5 li model, the entire aerobic granules were imaged respectively to excitement and emissions. The Z-sectioning is carried out on granules by Las Af Lite software and rendered in three dimensions.

\section{FINDINGS AND CONCLUSIONS}

\subsection{Aerobic Granules composition of EPS}

The performance of protein and polysaccharide in remaining aerobic granules' structural capacity were examined by Seviour et al. (2012). They noted the 
hydrolysis of extracellular proteins in the aerobic granulated EPS matrix caused the EPS matrix to collapse and subsequent aerobic granulated disintegration. These findings proposed that extracellular proteins would be vital if the EPS matrix of aerobic granules is to maintain structural stability. Similarly, a decrease in the protein-to-polysaccharide ratio in the EPS matrix is commonly regarded as a sign of weakening granule structure (Miao et al. 2019). In fact, polysaccharide is more susceptible to biological and chemical degradation than proteins because of the easy molecular structure. Granules with low protein to polysaccharide ratios therefore have a matrix of fragile structural elements.

The functional group of chemical is essential in identifying the active chemical through electrostatic, hydrogen bonding or ionic appealing forces of EPS stabilization. In differences of functional groups for EPS aerobic granules are defined with evaluating the spectral of FTIR between day 0 to 105 which shown in Fig. 1. The distinctive FTIR spectrum analysed is according to research guidelines (Schmitt and Flemming 1998; Omoike and Chorover 2004).

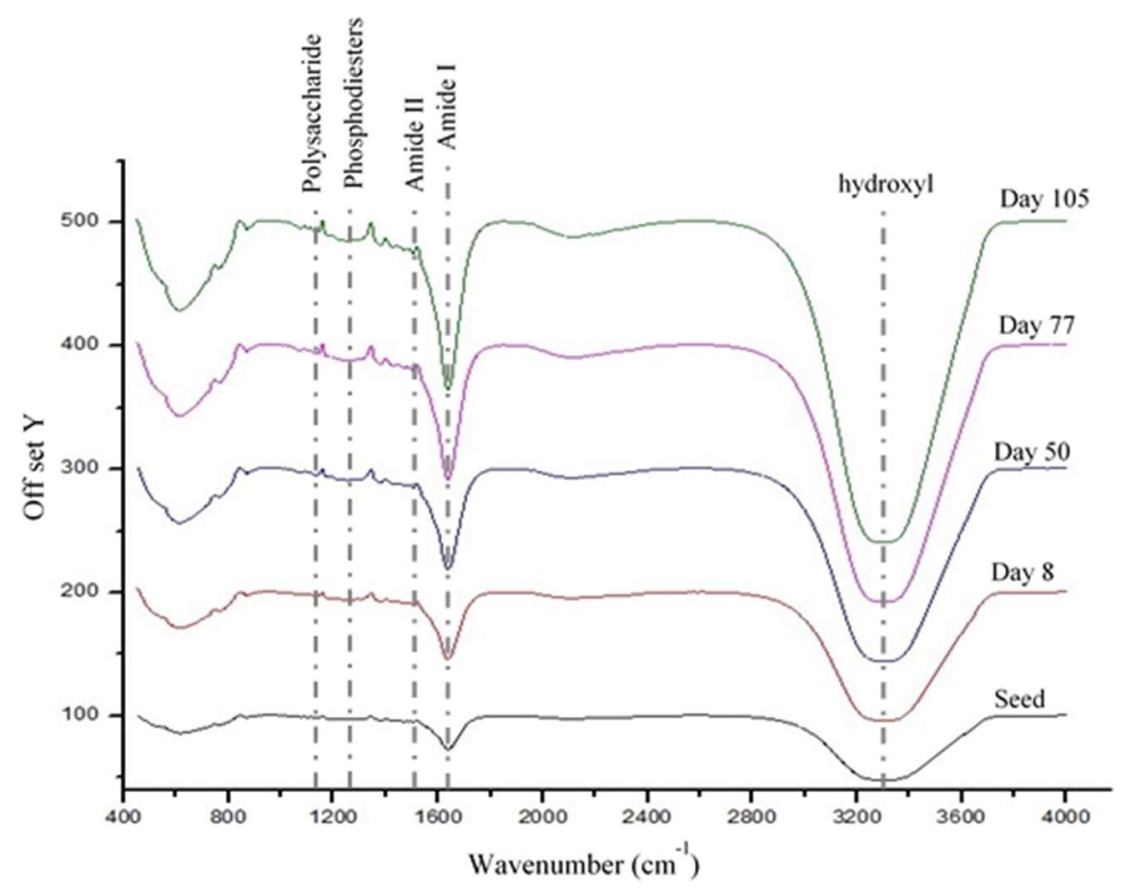

Fig. 1. Freezing EPS for FTIR spectral from seed to day 105

Fig. 1 demonstrated a good vibration by amide I on $1638 \mathrm{~cm}^{-1}$ whereas weakened wave by amide II on $1505 \mathrm{~cm}^{-1}$ which noted of existing the protein in overall EPS samples. The amide $\mathrm{I}$ in a range 1630 to $1640 \mathrm{~cm}^{-1}$ which is correlated with $\mathrm{C}=\mathrm{O}$ 
stretching wave $\beta$-sheet at structure of auxiliary proteins which preferred bio flocking (Badireddy et al. 2010; Zhu et al. 2012). While weakened wave by amide band II stated the predominance of $\mathrm{C}=\mathrm{O}$ stretching relative to $\mathrm{C}-\mathrm{N}$ stretching, $\mathrm{N}$ $\mathrm{H}$ bending and $\mathrm{O}=\mathrm{C}-\mathrm{N}$ bending. All EPS samples was functional group by polysaccharides between 1134 to $1136 \mathrm{~cm}^{-1}$. The finding of Omoike and Chorover (2004) was ranging within 900 and $1200 \mathrm{~cm}^{-1}$ are the result of polysaccharide bond or DNA / RNA correlate by $\mathrm{O}-\mathrm{H}$ and $\mathrm{C}-\mathrm{O}$ vibration stretching. The weakened wave of wide phosphodiester bonds was observed at Day 50, Day 77, and Day 105 between 1259 and $1263 \mathrm{~cm}^{-1}$ noted a low levels by nucleic acids of samples. The study by Badireddy et al. (2010) have shown that a wide ester band in a range of 1270 and $1230 \mathrm{~cm}^{-1}$ indicates an adhesion, cell aggregation and integrity of biofilm. In addition, the FTIR range verified a dynamic existing $3303 \mathrm{~cm}^{-1}$ of hydroxyl.

Contrasted with seed, amide I and amide II also the polysaccharides of aerobic granules FTIR transmittance intensities arise with duration of re-formation. It was a signal to enhance aerobic granules stability characteristics over the formation period. Compounds likes enzymes, alcohol and polysaccharides carrying of $\mathrm{C}=$ $\mathrm{O}, \mathrm{C}-\mathrm{O}$ and $\mathrm{O}-\mathrm{H}$ help and support all of microorganisms for the stabilization of the EPS matrix by appealing hydrogen bonding and ionic or electrostatic forces (Flemming and Wingender 2010). In other side, the aggregation process was hindered by functional groups such as acetal, carboxylate, carbonyl or hemiacetal and hydrocarbons (Omoike, A and Chorover 2004). In addition, the relationship between the EPS parts that with Van der Waals also enables to present the stability of EPS.

As a consequence, the ionizable organizations displayed on the surface of cell aggregates will decline and eventually decrease the polar relationship between EPS and water molecules to encourage hydrophobicity of cells (Wang et al. 2006). Therefore, thermodynamically, which raise in hydrophobicity cell simultaneously depict a reduction in the surface's surplus Gibss energy, which is turn encourages liquid phase cell self-aggregation to create a next of solid phase (Liu and Tay 2004; Liu et al. 2009).

The Localized spectral assessment by EDX noticed that the complete proportion of carbon or oxygen components by seed are close to $90 \%$. Increasing the existence of components such as aluminium, iron and sodium subsequently recommended the presentence of effective ionic forces in aerobic granules with dissociated $\mathrm{C}=\mathrm{O}$, also divalent metal cations $(\mathrm{Ca} 2+$ and $\mathrm{Fe} 2+)$ as well as $-\mathrm{H}$ bonding within $\mathrm{O}-\mathrm{H}$ and the monovalent cations $(\mathrm{K}+, \mathrm{Na}+)$. The combination of EDX and FTIR outcomes demonstrates that intermolecular interaction that resulted the stability with EPS. 


\subsection{Aerobic Granules distribution of EPS}

EPS plays a major role in the structure and morphology of AGS. The role of individual elements of the EPS matrix on AGS stabilization has not yet been explained on the basis of the research published in the literature. One of the factors might be the technique of extraction. As mentioned by Adav and Lee (2008), it was hard owing to their compact composition to extract EPS from aerobic granules.

In this research, the work were performed with multicolor fluorescence to explore the EPS dispersion and granulated cells. Fig. 2 showed the display on day 0 (seed), 50 and 105 of comparison picture by all aerobic granules. The fluorescent pictures were tested at day 0 , day 50 at the center and day 105 from the center noted 7.8 $\mu \mathrm{m}, 14 \mu \mathrm{m}$ and $6.3 \mu \mathrm{m}$, respectively. The measurement of thickness size of aerobic granules by CLSM image was expressed in the Z-sectioning that shown in Fig. 3.

The comparison picture (a), a lengthy preserve at $5^{\circ} \mathrm{C}$ aerobic granules may have led to a rare structure (day 0). As comparison, the aerobic granules at day 50 with 105 noted the compact structure. The picture assessment at various Z-sections at day 0 with 50 showed the dispersion of $\beta$-D-glucopyranose polysaccharides conscious overall aerobic granules, whereas the central consisted of proteins and active cells such as nucleic acid. The test of the image of various $Z$-sections at day 105 noted the elevated fluorescent intensity of protein and also an active cells is between $56 \mu \mathrm{m}$ by the outside surface. A protein and active cell layer density was spread throughout the entire aerobic granules with $\beta$-D-glucopyranose polysaccharides within $7 \mu \mathrm{m}$.

Remark, for all aerobic granules tested, the fluorescence force of $\beta$-Dglucopyranose polysaccharides at the central layer was greater compared to outer layer. However, in the study of Chen et al. (2007) found that protein and $\beta$-Dglucopyranose formed in an acetate-fed granules, while the outer layers accumulated cells and $\alpha$-D-glucopyranose.

In this study the findings are compatible with Chen et al. (2007) noted the polysaccharides of $\beta$-D-glucopyranose does not only condensed by exterior layer, yet were distributed throughout the inner granules. Whereas, McSwain et al. (2005) detected a several indicator of active cells from the center of aerobic granules and suggested the specimen was produced in flocs or lower size of aerobic granules which is cells and EPS were presented at the center as together. The typical size of aerobic granules within day 0 (seed), 50 also at day 105 was below than $700 \mu \mathrm{m}$, and can grouped as small sizes that was noted in our past report (Awang et al. 2017). The picture on day 50(a) was in combination with the aerobic granule microscope pictures between day 46 and 67 that shows the obvious presence of filamentous microorganism emerging from thick aggregates 
was influenced by small CODs and this may cause low particle density and lower mechanical strength (Seviour et al. 2012).

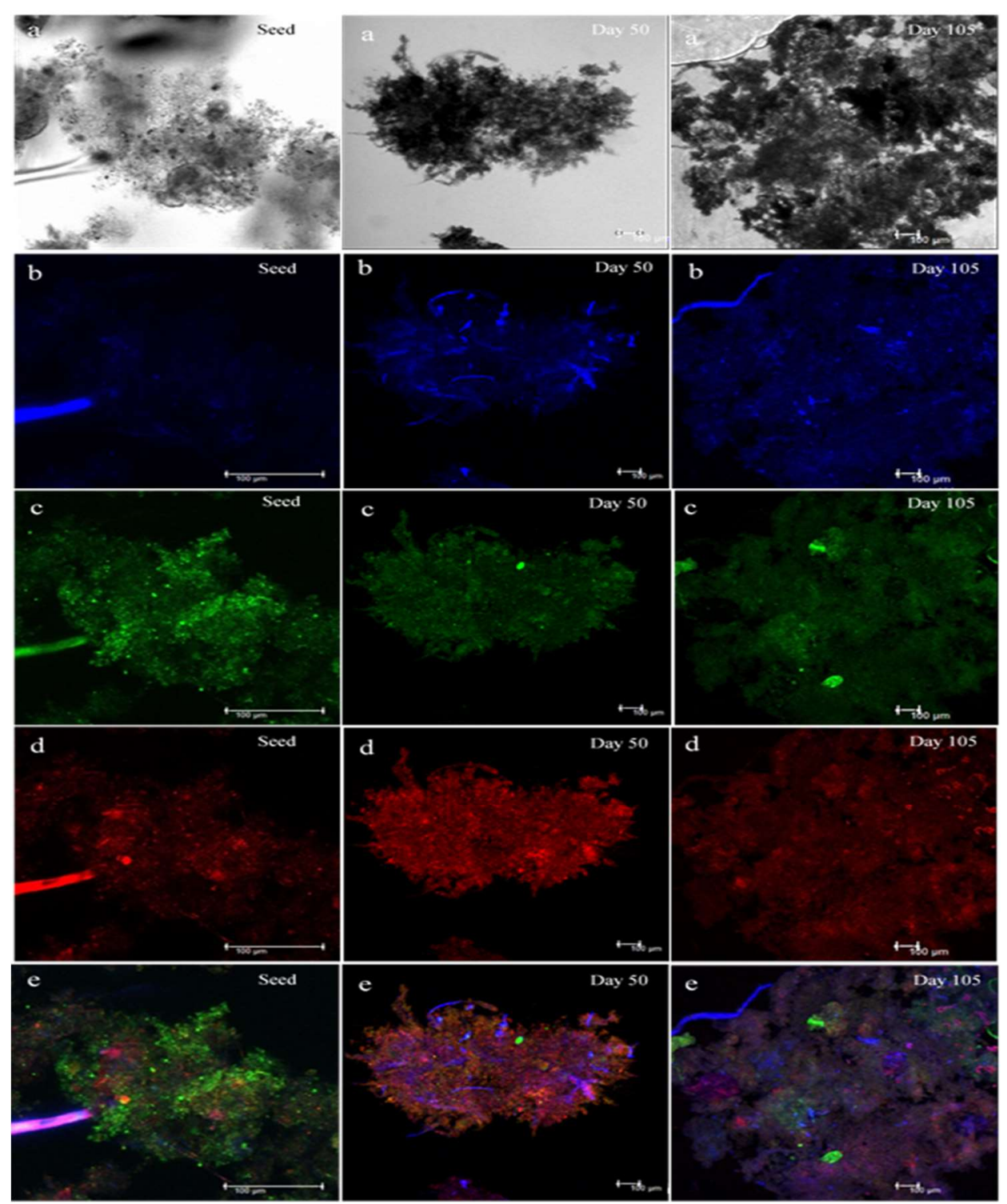

Fig. 2. Illustration of CLSM of aerobic granules at day 0 (seed), 50 and 105;

a) comparison picture, b) Polysaccharides $\beta$-D-glucopyranose by calcofluor white, c) the protein using FITC kit, d) the nuclei acid with SYTO 63,

e) an overlay picture of b)-d) 


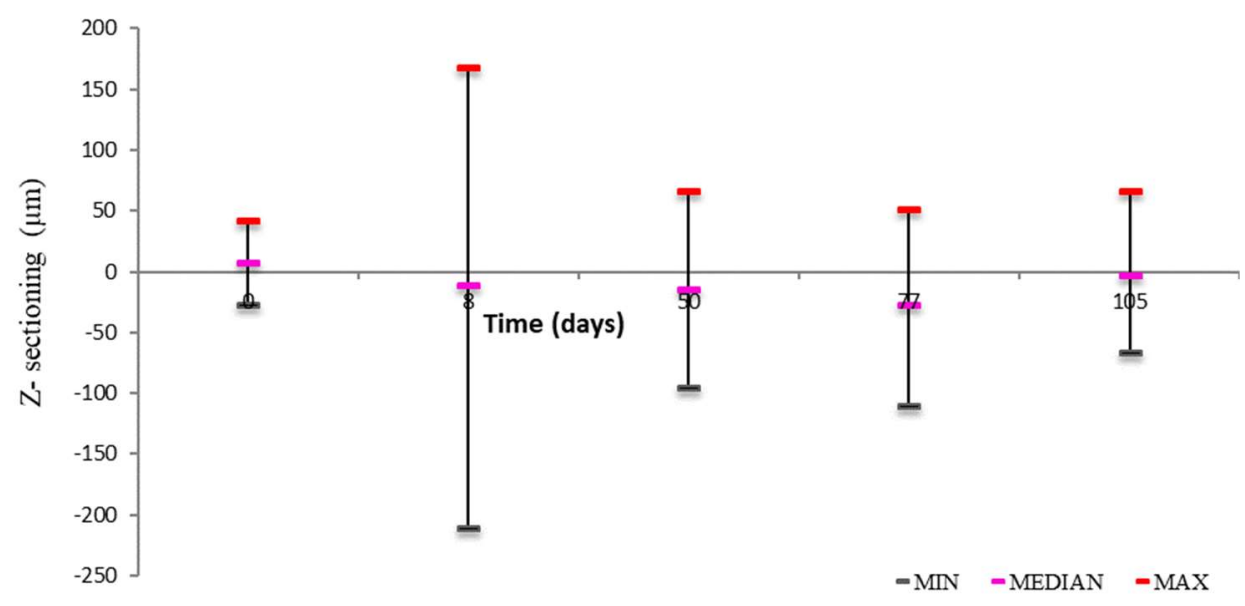

Fig. 3. The Z-sectioning by overall aerobic granules within day 0 to 105

The overlay pictures on day 50(e) further disclosed that $\beta$-D-glucopyranose polysaccharides was similar to reinforce protein and active cell surface to prevent aerobic granules from disintegrating. This noted the outline made by Zhu et al. (2012) on $\beta$-polysaccharides that created a constant and embedded structure which is smooth core for aerobic granules like mesh skeletons which favored the stabilization development. Related to the FTIR spectral analysis, FITC, calcofluor white and SYTO 63 fluorescence intensities of aerobic granules may improve in conjunction with the duration of reformation.

\section{CONCLUSION}

The combination of EDX and FTIR outcomes demonstrates that intermolecular interaction has helped the EPS stabilization. CLSM analysis regarded the $700 \mu \mathrm{m}-$ sized aerobic granules to be tiny and comparatively stable. That is commit by polysaccharides of $\beta$-D-glucopyranose, which develop by the interior granules.

\section{ACKNOWLEDGEMENT}

This study was sponsored by University of Malaya research grants (RG16012SUS and PV038-2012A) and Department of Higher Education Malaysia (FP041-2013B). Hamiruddin, NA acknowledges Research University Individual Grant (1001/PAWAM/8014038) granted by Universiti Sains Malaysia for sponsorship as Research Assistance. 


\section{REFERENCES}

1. Adav, SS and DJ Lee 2008. Extraction of extracellular polymeric substances from aerobic granule with compact interior structure. Journal Hazard Material 154, 1120-1126.

2. Adav, SS, Lee, DJ and Tay, JH 2008. Extracellular polymeric substances and structural stability of aerobic granule. Water Resource 42, 1644-1650.

3. Awang, NA, Shaaban, MG, Weng, LC and Wei, BC 2017. Characterization of aerobic granular sludge develop under variable and low organic loading rate. Sains Malaysia 46, 2497-2506.

4. Badireddy, AR, Chellam, S, Gassman, PL, Engelhard, MH, Lea, AS and K.M. Rosso, KM 2010. Role of extracellular polymeric substances in bioflocculation of activated sludge microorganisms under glucosecontrolled conditions. Water Resource 44, 4505-4516.

5. Chen, Y, Jiang, W, Liang, DT and Tay, JH 2007. Structure and stability of aerobic granules cultivated under different shear force in sequencing batch reactors. Applied Microbiology Biotechnology 76, 1199-1208.

6. Flemming, $\mathrm{HC}$ and Wingender, J 2010. The biofilm matrix. Nature Revise Microbiology 8, 623-633.

7. Lee, DJ, Chen, YY, Show, KY, Whiteley, CG and Tay, JH 2010. Advances in aerobic granule formation and granule stability in the course of storage and reactor operation. Biotechnology Advance 28, 919-934.

8. Liu, XW, Sheng, GP and Yu, HQ 2009. Physicochemical characteristics of microbial granules. Biotechnology. Advance 27, 1061-1070.

9. Liu, Y and Tay, JH 2002. The essential role of hydrodynamic shear force in the formation of biofilm and granular sludge. Water Resource 36, 1653-1665.

10. Liu, Y and Tay, JH 2004. State of the art of biogranulation technology for wastewater treatment. Biotechnology Advance 22, 33-563.

11. Mcswain, BS, Irvine, RL, Hausner, M and Wilderer, PA 2005. Composition and Distribution of Extracellular Polymeric Substances in Aerobic Flocs and Granular Sludge. Applied Environment Microbiology 71, 1051-1057.

12. Miao, L, Yang, G, Tao, T and Peng, Y 2019. Recent advances in nitrogen removal from landfill leachate using biological treatments - A review. Journal of Environmental Management 235, 178-181.

13. Nancharaiah, YV and Reddy, KK 2018. Aerobic granular sludge 
technology: Mechanisms of granulation and biotechnological applications. Bioresour. Technol 247, 1128-1143.

14. Omoike, A and Chorover, J 2004. Spectroscopic Study of Extracellular Polymeric Substances from Bacillus subtilis : Aqueous Chemistry and Adsorption Effects. Biomacromolecules 5, 1219-1230.

15. Pishgar, R, Dominic, JA, Sheng, Z and Tay, JH 2018. Influence of operation mode and wastewater strength on aerobic granulation at pilot scale: Startup period, granular sludge characteristics, and effluent quality. Water Research 160, 81-96.

16. Schmitt, J and Flemming, H 1998. FTIR-spectroscopy in microbial and material analysis. International Biodeterioration Biodegradation 41, 111.

17. Seviour, T, Yuan, Z, Van Loosdrecht, MCM and Lin, Y 2012. Aerobic sludge granulation: a tale of two polysaccharides. Water Resource 46, 4803-4813.

18. Sheng, GP, Yu, HQ and Li, XY 2010. Extracellular polymeric substances (EPS) of microbial aggregates in biological wastewater treatment systems: A review. Biotechnology Advance 28, 882-894.

19. Tay, JH, Liu, QS and Liu, Y 2001. The role of cellularpolysaccharides in the formation and stability of aerobic granules. Applied Microbiology 33, 222-226.

20. Val Del Río, A, Figueroa, M, Mosquera-Corral, A, Campos, JL and Méndez, R 2013. Stability of aerobic granular biomass treating the effluent from a seafood industry. International Journal Environmental Resource 7, 265-276.

21. Wang, ZW, Liu, Y and Tay, JH 2005. Distribution of EPS and cell surface hydrophobicity in aerobic granules. Applied Microbiology Biotechnology 69, 469-473.

22. Wang, Z, Liu, L, Yao, J and Cai, W 2006. Effects of extracellular polymeric substances on aerobic granulation in sequencing batch reactors. Chemosphere 63, 1728-1735.

23. Zhu, L, Lv, M, Dai, X, Yu, Y, Qi, H and Xu, X 2012. Role and significance of extracellular polymeric substances on the property of aerobic granule. Bioresource Technology 107, 46-54.

Editor received the manuscript: 12.08.2019 